\title{
Job Turnover, Unemployment and Labor Market Institutions
}

\author{
G. Joseph, O. Pierrard and H.R. Sneessens* \\ IRES \\ Université catholique de Louvain \\ Louvain-la-neuve
}

\begin{abstract}
This paper studies the role of labor market institutions on unemployment and on the cyclical properties of job flows. We construct an intertemporal general equilibrium model with search unemployment and endogenous job turnover, and examine the consequences of introducing an unemployment benefit, a firing cost and a downward wage rigidity. The simulations suggest that downward wage rigidities, rather than unemployment benefit or firing cost, may well play a dominant role in explaining both the high unemployment rate and the job flows dynamics of such an economy.
\end{abstract}

Keywords: Unemployment, Job flows dynamics, Institutions.

JEL classification: E24, J38, J63, J65.

${ }^{*}$ The third author is also at the Université Catholique de Lille and IZA, Bonn. Contact author: Olivier Pierrard, IRES, 3 place Montesquieu, B-1348 Louvain-la-Neuve, phone: +32 10 473508, fax: +32 10 473945, email: pierrard@ires.ucl.ac.be. This research is part of a project financed by the Service des Etudes et de la Statistique (SES) of the Walloon Region, Belgium. We also benefited from the financial support of the PAI-UAP federal research programme P5/10/28. 


\section{Introduction}

A number of empirical papers suggest that cross country differences in job dynamics and employment may be related to institutional differences by generating distinct responses to similar shocks (see for instance Nickell [18], Blanchard and Wolfers [4], Bertola et al. [3]). It is also now well-known that there is no simple relationship between the dynamic behavior of the labor market and the aggregate unemployment level. Unemployment rates are typically higher in Europe than in the US, although job turnover rates, the sum of the job destruction and the job creation rates, look fairly similar (see OECD [19] and [20]). The institutional features emphasized by the literature as most important for aggregate employment performance are the generosity of the unemployment insurance system and the characteristics of the wage negotiation process. Employment protection measures have no clear effect on aggregate employment, although they may obviously affect the job reallocation process.

In theoretical literature, much effort has been devoted to investigate the behaviors and mechanisms able to explain these empirical findings by relying on models with endogenous job creation and destruction (see Mortensen and Pissarides [16]). In this framework, unemployment benefits affect positively the worker's bargaining position and therefore the negotiated wages. The effect on employment is hence negative ${ }^{1}$. Employment protection unambiguously limits job destruction but also job creation, so that the net effect on total employment is a priori ambiguous. However, in most of the calibrated models, a positive relationship is often found (see Mortensen and Pissarides [17] or Ljungqvist [14]). A much less analyzed issue is the effect of wage rigidities on job flows. An exception is Cahuc and Zylberberg [7] who investigate the interaction between job protection and minimum wage restrictions. They start from a standard model where, with freely negotiated wages, firing costs have a positive impact on employment, as in Mortensen and Pissarides [17]. They show that this conclusion can be reversed when wages negotiations are constrained by a minimum wage rule.

Our objective is to build on these previous works and look more closely at the combined effects of three institutional characteristics of the labor market: unemployment benefits, employment protection and wage rigidities. We build to that end a stochastic intertemporal

\footnotetext{
${ }^{1}$ See for instance Holmlund [12] for a survey on unemployment benefits.
} 
general equilibrium model with search unemployment and endogenous job turnover. This gives us the mean to examine the effects of these institutional variables, on both the stationary state values of unemployment and job flows and on their cyclical properties. Looking at cyclical properties gives additional information about the combined effects of institutional variables and about their role in explaining the similarities and differences between the US and a typical European country. Garibaldi [11] studies the effects of institutions on the cyclical properties of job flows. However, he does not introduce capital accumulation and he only assumes three possible aggregate states (bad, medium and good) for his economy. He moreover solely focuses on employment protection (through flows of firing permissions). Our starting point is Den Haan et al. [10], who insert the Mortensen and Pissarides [16]'s model into an intertemporal general equilibrium model, with endogenous interest rates and capital accumulation. One can in this way capture the interactions between capital accumulation and job destruction. The model also distinguishes two types of shocks, an autoregressive aggregate productivity shock and a job specific idiosyncratic productivity shock, so as to be able to examine both the cyclical and the stationary state properties of the economy. In our paper, we complete this framework by introducing the three above-mentioned labor market institutions. Unemployment benefits are exogenous and employment protection takes the form of a firing tax. The downward wage rigidity is modelled as a lower bound on the outcome of wage negotiations: wages are renegotiated "at will" according to a Nash bargaining rule as long as they remain above this institutionally determined lower bound ${ }^{2}$.

The model is calibrated so as to reproduce the main characteristics of an "average" EU economy $^{3}$, in terms of unemployment rate and job flows levels and volatilities. The model so calibrated yields a procyclical job creation rate, a countercyclical job destruction rate and a weakly countercyclical job turnover. The calibrated model is next used as a benchmark to evaluate the role played by each of our institutional variables. Unemployment benefits have a sizeable effect on the unemployment rate, not so much though as the wage rigidity.

\footnotetext{
${ }^{2}$ Wage rigidities may take much more subtle forms and be much more pervasive than "minimum wage" restrictions (see Cahuc and Zylberberg [7] for a more elaborated representation of downward wage rigidities). However, as these authors, we will refer throughout the paper to the lower bound of the wage distribution as a minimum wage, keeping in mind that it is not associated with the worker productive characteristic. Indeed, all individuals in our model strictly have the same skills and only jobs productivity differs.

${ }^{3}$ Except UK which do not share many labor market characteristics of most continental European countries.
} 
As in Cahuc and Zylberberg [7], the effect of employment protection depends on the level of the wage rigidities. Low rigidities are associated with a positive effect of the firing tax on employment while high rigidities are associated with a negative effect. However, whatever the rigidities, the quantitative effect of employment protection is weak. We also obtain that changes in the wage rigidity and in the firing tax have opposite effects on the cyclical properties of job flows, while changes in the unemployment benefit have almost no effects. A wage rigidity decreases the relative job destruction rate volatility (with respect to the job creation rate volatility) and decreases the countercyclicality of the job turnover. This suggests that downward wage rigidities, rather than unemployment benefit and employment protection, may well play a dominant role in explaining the differences between the US and the EU economies, both in terms of equilibrium unemployment rate and of the cyclical properties of job flows.

The rest of the paper is organized as follows. In the next section, we summarize some key empirical findings about the working of labor market, in OECD countries, and we give some estimates of the relative importance of unemployment benefits, job protection and wage rigidities. In section 3, we present our theoretical framework. The model is then calibrated in section 4 and simulated in section 5 to provide a quantitative assessment of the effects of our institutional variables on the steady state and the cyclical properties. The last section concludes.

\section{Labor market flows and institutions: some stylized facts}

In this section, we briefly report some empirical evidences about labor market flows and institutional characteristics for several OECD countries.

\subsection{Job turnover and unemployment}

Many contributions have attempted to assess the cyclical behavior of labor market flows in order to highlight the differences or similarities between European and North American countries. A particular attention has then been devoted to the job turnover rate $(J T)$, 
the sum of job creation $(J C)$ and job destruction rates $(J D)$, and its correlation with net employment changes ${ }^{4}$.

An important feature regarding job flows dynamics is that, in most OECD countries, the job turnover is relatively high, between $15 \%$ and $25 \%$ (see second column of table 1). This observation is more striking if we consider the third column of table 1, which provides the net employment change rate $(N E T)$, defined simply as the difference between $J C$ and $J D^{5}$. It turns out indeed that a slightly positive net employment change is associated with a very large job reallocation. If a high average level of job turnover is a common feature of most OECD countries, we nevertheless observe differences across countries in the job turnover cyclical properties. Looking at the fourth and fifth columns, we notice that in the US, the $J D$ rate is more volatile than the $J C$ rate. On the other hand, in the EU, the volatilities of the $J D$ rate and the $J C$ rate are quite close (see column 6 ).

Another well known empirical finding is that, generally, job creation is procyclical while job destruction is countercyclical. It indeed seems intuitive enough to have more (resp. less) job creations and less (resp. more) job destructions during economic expansion (recession). A much more open and debated question concerns the cyclicality of job turnover. This has been sudied by several authors ${ }^{6}$ but with sometimes quite different results given the data and the methodology used. The OECD [19] proposes a summary of these studies and it usually turns out that in the US, the job turnover is negatively correlated with the net employment change rate, whereas in the EU, the correlation seems to be much less negative ${ }^{7}$. Consequently, in the US, the level of job reallocation is higher during a recession, while in the $\mathrm{UE}$, it is quite constant over the cycle. It is worth noting that this observation is consistent with the more important job destruction volatility in the US. Eventually, as displayed in the last column of table 1 , the unemployment rate is lower in the US than in the EU.

\footnotetext{
${ }^{4}$ Due to a lack of quarterly data (especially for European countries), all figures presented in this section are annual data.

${ }^{5}$ See OECD [19] for extensive definitions of these concepts.

${ }^{6}$ See, among others, Davis et al. [9] for the US and Boeri [5] for some OECD countries.

${ }^{7} \mathrm{NET}$ is taken as a measure of the cycle in empirical papers. Data are also HP filtered.
} 


\subsection{Labor market institutions}

In table 2, we provide for several OECD countries some measures of three policy instruments that we will study in our theoretical model: unemployment insurance, employment protection and wage rigidities. The simultaneous use of these instruments is often regarded as a significant factor to explain the weak performance (in term of employment) of European labor markets.

Using different unemployment durations (from 1 to 5 years) and different marital status (single, couple without children, couple with two children), the OECD [24] computes a synthetical net replacement ratio for 1999. This statistics (second column of table 2) is twice higher in most EU countries $^{8}$ than in the US. This underlines the relative generosity of the unemployment benefits in the EU countries (or the tightness in the US). In the same way, the OECD [23] computes a synthetical index of the strictness of the employment protection legislation for the end 1990's. This indicator (first figure of the third column) includes regular and temporary contracts and takes into account the regular procedural inconveniences, the notice and severance pay for no-fault individual dismissals and the difficulty of dismissal. A low (resp. high) index means a low (resp. high) protection of employment. The OECD also ranks the 26 countries surveyed from the country with the less strict protection (rank 1) to the country with the strictest protection (rank 26). This ranking is given between parentheses in the third column. We again observe a sharp difference between the EU (with strong employment protection) and the US (with almost no employment protection) situations. Eventually, we reproduce in the fourth column of table 2 the gross Kaitz index given by the OECD [22] for the year 1997. The Kaitz index is here defined as the ratio between the minimum wage and the gross full-time mean earnings. This Kaitz index is over 0.50 for the EU countries whereas it is of only 0.35 for the US. Another way to illustrate the rigidities of the EU wages is to look at the ratio between the highest and the lowest wages. The last column of table 2 gives the D9/D1 ratio $^{9}$ (see OECD [21]). The obvious conclusion is that the wage dispersion is substantially lower in EU countries. This may be the result

\footnotetext{
${ }^{8}$ The replacement ratio in Italy is quite low and even lower than in the US. This ratio however rapidly increases over time.

${ }^{9} \mathrm{D} 1$ and D9 refer to the upper earnings limits of, respectively, the first and the ninth deciles of employees ranked in order of their gross earning from lowest to highest.
} 
of downward wage rigidities induced by minimum wage legislation, collective agreements negotiated by more powerful trade unions,...

\section{Model}

To formalize the economy, we start from the Pierrard and Sneessens [25] two-tier productive structure by assuming the coexistence of three types of agents in the economy: intermediate firms, a representative final firm and a representative household ${ }^{10}$. Intermediate firms require one worker to produce $x$ units of intermediate good. As in Mortensen and Pissarides [16], $x$ is a random job-specific productivity parameter drawn each period from a general cumulative distribution function $F^{11}$. The final firm uses intermediate goods as well as capital to produce an homogeneous final good that can be either consumed or invested by the household. This representative household supplies labor to intermediate firms and capital to the final firm. We then have three types of markets for respectively labor, goods and capital. We use a standard matching function to represent the frictions on the labor market. The household search effort is endogenous, as well as the job creation and destruction rates. The final good is taken as the numeraire. Perfect competition prevails on both goods and capital market. Finally, the wages are negotiated between the intermediate firms and the household. There is however an institutionally fixed lower bound wage binding downward the negotiation results (downward wage rigidity). We also introduce unemployment benefits and employment protection.

\footnotetext{
${ }^{10}$ We could equivalently assume, as in den Haan et al. [10], a "one-tier" production structure with only single job firms with labor but also capital as input. Our two-tier structure (intermediate and final firms) however allows a simpler presentation.

${ }^{11}$ The assumption that the idiosyncratic shock arrival rate is equal to 1 (as for instance in den Haan et al. [10]) greatly simplifies our model. Introducing some persistence for these shocks would indeed necessitate to use a discrete aggregate productivity shock (see Mortensen and Pissarides [17] or Garibaldi [11] for such aggregate productivity shock) rather than the usual specification used in Real Business Cycle models (see equation (43)).
} 


\subsection{Labor market flows}

We assume that the total labor force is constant and normalized to 1 , with $N_{t}$ employed workers and $U_{t}$ unemployed workers:

$$
1=N_{t}+U_{t}
$$

At each period, the number $M_{t}$ of new employer-worker contacts is function of the stock $V_{t}$ of vacancies and of the number of efficient job seekers, i.e. the number of unemployed weighted by a function $\mathcal{S}$ of their search effort $S_{t}$. More formally:

$$
M_{t}=\mathcal{M}\left(V_{t}, \mathcal{S}\left(S_{t}\right) U_{t}\right),
$$

where the matching function $\mathcal{M}$ is increasing, concave in its arguments and $\mathcal{M}(0,)=$. $\mathcal{M}(., 0)=0$. The function $\mathcal{S}$ is increasing, concave and $0 \leq S_{t}$. The probability for a firm with a vacancy to meet a job seeker is $q_{t}$ and the probability for a job seeker to meet a vacancy is $p_{t}$, and they are respectively given by:

$$
q_{t}=\frac{M_{t}}{V_{t}} \quad \text { and } \quad p_{t}=\frac{M_{t}}{\mathcal{S}\left(S_{t}\right) U_{t}}
$$

It is worth noting that all contacts will not lead to job creation because some matches may turn out not to be productive enough. The productivity $x$ of a new match is only revealed after the contact and may be too low to generate a positive surplus. The endogenous destruction rate of the new contacts will be denoted $\chi_{t}^{0}$, whereas the endogenous destruction rate of existing jobs is $\chi_{t}^{1}$. As we will see later, the difference between these two rates arises from the fact that only existing jobs are institutionally protected. Total employment is therefore the sum over two different types of jobs: "new jobs" (new contacts not destroyed) denoted by the superscript $j=0$ and "old jobs" (existing jobs not destroyed) denoted by the superscript $j=1$. The dynamics of total employment is given by the following equations, respectively in terms of vacancies and job seekers' search effort:

$$
\begin{aligned}
& N_{t+1}=N_{t+1}^{0}+N_{t+1}^{1}=\left(1-\chi_{t+1}^{0}\right) q_{t} V_{t}+\left(1-\chi_{t+1}^{1}\right) N_{t}, \\
& N_{t+1}=N_{t+1}^{0}+N_{t+1}^{1}=\left(1-\chi_{t+1}^{0}\right) p_{t} \mathcal{S}\left(S_{t}\right) U_{t}+\left(1-\chi_{t+1}^{1}\right) N_{t} .
\end{aligned}
$$




\subsection{Intermediate firms}

As explained before, a new contact at time $t$ will lead to job creation at time $t+1$ if hit by an idiosyncratic productivity shock higher both than the reservation productivity $R_{t+1}^{F, 0}$ for the intermediate firm and $R_{t+1}^{H, 0}$ for the household. The reservation productivity of the economy is therefore given by $R_{t+1}^{0}=\max \left\{R_{t+1}^{F, 0}, R_{t+1}^{H, 0}\right\}$ and the asset value of an intermediate firm with a vacancy, $W_{t}^{V}$, is:

$$
\begin{aligned}
& W_{t}^{V}=-a+\left(1-q_{t}\right) \tilde{\beta}_{t} \mathrm{E}_{t}\left[W_{t+1}^{V}\right]+ \\
& q_{t} \tilde{\beta}_{t} \mathrm{E}_{t}\left[F\left(R_{t+1}^{0}\right) W_{t+1}^{V}+\int_{R_{t+1}^{0}}^{+\infty} W_{t+1}^{F, 0}(z) d F(z)\right]
\end{aligned}
$$

$a$ is the cost of opening a vacancy, $\tilde{\beta}_{t}$ is the discount variable for future profits (defined in the next section) and $W_{t}^{F, 0}$ is the asset value of a new job. The asset value of an intermediate firm with a job of type $j \in\{0,1\}$ and with a productivity $x$ is:

$$
\begin{aligned}
& W_{t}^{F, j}(x)=x d_{t}-w_{t}^{j}(x)+ \\
& \tilde{\beta}_{t} \mathrm{E}_{t}\left[F\left(R_{t+1}^{1}\right)\left(W_{t+1}^{V}-f\right)+\int_{R_{t+1}^{1}}^{+\infty} W_{t+1}^{F, 1}(z) d F(z)\right] .
\end{aligned}
$$

$d_{t}$ is the unit price of the intermediate goods, $f$ the firing tax, $R_{t}^{1}$ the economy reservation productivity for an old job $\left(R_{t+1}^{1}=\max \left\{R_{t+1}^{F, 1}, R_{t+1}^{H, 1}\right\}\right)$ and $w_{t}^{j}(x)$ the wage. For the moment, we suppose a completely general wage formation mechanism $w_{t}^{j}: \Re \rightarrow \Re: x \rightsquigarrow w_{t}^{j}(x)$. We will see in section 3.5 how we introduce the wage bargaining with the downward wage rigidity. It is worth pointing out that the distinction between the two asset values $W_{t}^{F, 0}(x)$ and $W_{t}^{F, 1}(x)$ comes from the fact that $w_{t}^{0}(x) \neq w_{t}^{1}(x)$ for given $x$. This is, in turn, due to the fact that new contacts are not protected by a firing tax ${ }^{12}$. The reservation productivity $R_{t}^{F, 0}$ for a firm with a new contact is therefore determined by:

$$
W_{t}^{F, 0}\left(R_{t}^{F, 0}\right)=0 \text {. }
$$

\footnotetext{
${ }^{12}$ Mortensen and Pissarides [16] assume that a new job always starts at the highest available productivity and is therefore never severed during the first period. As pointed by Caballero and Hammour [6], this assumption is particularly suitable for growth models with creative destruction.
} 
However, the firms with an old job have to pay a firing tax if the match is severed and their reservation productivity $R_{t}^{F, 1}$ is therefore determined by ${ }^{13}$ :

$$
W_{t}^{F, 1}\left(R_{t}^{F, 1}\right)+f=0
$$

Finally, applying the free entry hypothesis, we also have at the equilibrium:

$$
W_{t}^{V}=0
$$

\subsection{Household}

Let the representative household's asset value be represented by the following function of the household's three state variables ${ }^{14}$ :

$$
W_{t}^{H}=W^{H}\left(K_{t}, N_{t}^{0}, N_{t}^{1}\right)
$$

where $K_{t}$ is the capital stock. It satisfies the following Bellmann equation:

$$
W_{t}^{H}=\max _{C_{t}, S_{t}}\left\{\mathcal{U}\left(C_{t}\right)-\mathcal{D}^{S}\left(S_{t}\right) U_{t}-\mathcal{D}^{N}\left(N_{t}\right)+\beta \mathrm{E}_{t}\left[W_{t+1}^{H}\right]\right\} .
$$

$C_{t}$ is consumption, $\mathcal{U}$ is an increasing and concave utility function, $\mathcal{D}^{S}$ and $\mathcal{D}^{N}$ are increasing and convex disutility functions (respectively of search and work) and $\beta$ is the discount parameter. Defining the average wage for a job of type $j$ by:

$$
\bar{w}_{t}^{j}=\frac{\int_{R_{t}^{j}}^{+\infty} w_{t}^{j}(z) d F(z)}{1-F\left(R_{t}^{j}\right)}
$$

the household's budget constraint then writes ${ }^{15}$ :

$$
C_{t}=\Pi_{t}+w^{u} U_{t}+\bar{w}_{t}^{0} N_{t}^{0}+\bar{w}_{t}^{1} N_{t}^{1}+\left(r_{t}+\delta\right) K_{t}-\left(K_{t+1}-(1-\delta) K_{t}\right)-T_{t}
$$

The profits redistributed by the intermediate firms (value added net of labor, firing and vacancy costs) are represented by $\Pi_{t}, w^{u}$ stands for the unemployment insurance, $\delta$ is the

\footnotetext{
${ }^{13}$ It is straightforward to note that with $f=0$ (no firing tax), we have $R_{t}^{F, 0}=R_{t}^{F, 1}, w_{t}^{0}(x)=w_{t}^{1}(x)$ and $W_{t}^{F, 0}(x)=W_{t}^{F, 1}(x)$.

${ }^{14} \mathrm{As}$ usual in most of the related literature, we assume a perfect insurance mechanism between the members of the household.

${ }^{15}$ As stated in Ljungqvist [14], severance payments can be offset by efficient labor contracts and have therefore no effects. It is why we rather focus here on a firing tax which is hence not paid to the laid off worker.
} 
capital depreciation rate and $T_{t}$ is a lump sum tax levied to finance the unemployment insurance. The optimization equation (12) is subject to the budget constraint (14) and equation (5). We can so derive the first order optimality conditions as follows:

$$
\begin{aligned}
& \mathcal{U}_{C_{t}}=\beta \mathrm{E}_{t}\left[\left(1+r_{t+1}\right) \mathcal{U}_{C_{t+1}}\right] \\
& \mathcal{D}_{S_{t}}^{S}=\beta p_{t} \mathcal{S}_{S_{t}} \mathrm{E}_{t}\left[\int_{R_{t+1}^{0}}^{+\infty} W_{N_{t+1}^{0}}^{H}(z) d F(z)\right] .
\end{aligned}
$$

$\mathcal{U}_{C_{t}}$ is the first derivative of $\mathcal{U}$ with respect to $C_{t}, \mathcal{D}_{S_{t}}^{S}$ the first derivative of $\mathcal{D}^{S}$ with respect to search intensity $S_{t}$. The household's marginal asset value $W_{N_{t}^{j}}^{H}$ of working on a job of type $j$, is given by the envelope theorem:

$$
\begin{gathered}
W_{N_{t}^{j}}^{H}(x)=\mathcal{U}_{C_{t}}\left(w_{t}^{j}(x)-w^{u}\right)+\mathcal{D}^{S}\left(S_{t}\right)-\mathcal{D}_{N_{t}^{j}}^{N}+ \\
\beta\left(1-p_{t} \mathcal{S}\left(S_{t}\right)\right) \mathrm{E}_{t}\left[\int_{R_{t+1}^{1}}^{+\infty} W_{N_{t+1}^{1}}^{H}(z) d F(z)\right],
\end{gathered}
$$

where $\mathcal{D}_{N_{t}^{j}}^{N}$ is the first derivative of $\mathcal{D}^{N}$ with respect to a job of type $j$.

For the household, the reservation productivity $R_{t}^{H, j}$ for a job of type $j$ is determined by:

$$
W_{N_{t}^{j}}^{H}\left(R_{t}^{H, j}\right)=0
$$

If, as already explained, the economy reservation productivity for a job of type $j$ is defined by $R_{t}^{j}=\max \left\{R_{t}^{F, j}, R_{t}^{H, j}\right\}$, then the job destruction rate $\chi_{t}^{j}$ for a job of type $j$ is $F\left(R_{t}^{j}\right)$. Moreover, taking into account that the firms are owned by the household, we are now able to define the discount parameter for the future profits:

$$
\tilde{\beta}_{t}=\beta \mathrm{E}_{t}\left[\frac{\mathcal{U}_{C_{t+1}}}{\mathcal{U}_{C_{t}}}\right] .
$$

\subsection{Representative final firm}

Let the asset value of the representative final firm be:

$$
W_{t}^{R}=W^{R}\left(K_{t}\right)
$$

where $Q_{t}$ is the quantity of intermediate goods. It satisfies the following Bellmann equation:

$$
W_{t}^{R}=\max _{Q_{t}, K_{t+1}}\left\{\mathcal{F}\left(K_{t}, Q_{t}\right)-\left(r_{t}+\delta\right) K_{t}-Q_{t} d_{t}+\tilde{\beta}_{t} \mathrm{E}_{t}\left[W_{t+1}^{R}\right]\right\}
$$


where $\mathcal{F}$ is an increasing and concave in its arguments production function which moreover satisfies $\mathcal{F}(0,)=.\mathcal{F}(., 0)=0$. The first order optimality conditions can then be written as follows:

$$
\begin{aligned}
& \mathcal{F}_{K_{t}}=r_{t}+\delta, \\
& \mathcal{F}_{Q_{t}}=d_{t} .
\end{aligned}
$$

Intermediate goods supplied by intermediate firms with a job of type $j$ is:

$$
Q_{t}^{j}=\frac{\int_{R_{t}^{j}}^{+\infty} z d F(z)}{1-F\left(R_{t}^{j}\right)} N_{t}^{j},
$$

and the total amount of intermediate goods is simply $Q_{t}=Q_{t}^{0}+Q_{t}^{1}$.

\subsection{Wage determination}

As usual, we assume that, at each period, wages are (re)negotiated between the firms and the representative household. These bargained wages can be determined by a fairly standard Nash product problem. The wage $w_{t}^{b, 0}(x)$ for new workers, not protected by a firing tax, is the solution of:

$$
\max _{w_{t}^{b, 0}(x)}\left(W_{t}^{F, 0}(x)-W_{t}^{V}\right)^{1-\eta}\left(\frac{W_{N_{t}^{0}}^{H}(x)}{\mathcal{U}_{C_{t}}}\right)^{\eta}
$$

while the wage $w_{t}^{b, 1}(x)$ for old workers, protected by a firing tax, is the solution of:

$$
\max _{w_{t}^{b, 1}(x)}\left(W_{t}^{F, 1}(x)-W_{t}^{V}+f\right)^{1-\eta}\left(\frac{W_{N_{t}^{1}}^{H}(x)}{\mathcal{U}_{C_{t}}}\right)^{\eta} .
$$

In both equations, $\eta$ represents the household's bargaining power. Using equations (6) to (10), equations (15) to (18) and the definition of $R_{t}^{j}$, bargained wages can be rewritten in the general form:

$$
w_{t}^{b, j}(x)=\eta\left(x-R_{t}^{j}\right) d_{t}+w_{t}^{b, j}\left(R_{t}^{j}\right)
$$

However, we introduce a wage rigidity in our economy in a sense that our negotiated wages are bounded downwards. If the wage $w_{t}^{b, j}$ solving equation (25) or (26) is below a lower bound $w^{m}$, then the firm must pay this lower bound. The critical productivity value $Q_{t}^{j}$ for which there is equality between the lower bound $w^{m}$ and the bargained wage $w_{t}^{b, j}(x)$ is defined by:

$$
w_{t}^{b, j}\left(Q_{t}^{j}\right)=w^{m}
$$


As a result, the wages can be written as:

$$
w_{t}^{j}(x)= \begin{cases}w^{m} & \text { if } x \leq Q_{t}^{j}, \\ w_{t}^{b, j}(x) & \text { if } x>Q_{t}^{j},\end{cases}
$$

and the bargained wage equation (27) can be rewritten in:

$$
w_{t}^{b, j}(x)=\eta\left(x-Q_{t}^{j}\right) d_{t}+w^{m} .
$$

From this equation, it is immediate that the lower bound of the wage distribution $w^{m}$ has a direct positive effect on the bargained wages, but also an indirect negative effect via an increase in the critical value $Q_{t}^{j}$.

Using some arithmetic, we can derive some analytical properties. Firstly, it is easy to check that without a wage rigidity, i.e. when $w^{m}$ is not binding, the decision to stop a match is jointly taken by the firm and the household. In other words:

$$
\text { if } Q_{t}^{j} \leq R_{t}^{j} \quad \text { then } \quad R_{t}^{F, j}=R_{t}^{H, j}=R_{t}^{j} .
$$

On the other hand, if some wages are bounded downwards, the decision to stop a match is always taken by the firm:

$$
\text { if } Q_{t}^{j}>R_{t}^{j} \quad \text { then } \quad R_{t}^{H, j}=-\infty \text { and } R_{t}^{F, j}=R_{t}^{j} .
$$

Secondly, we have the following relationships between the reservation productivities $R_{t}^{j}$, the critical values $Q_{t}^{j}$ and the bargained wages $w_{t}^{b, j}(x)$, of the new jobs and the old jobs:

$$
\begin{aligned}
\left(R_{t}^{0}-R_{t}^{1}\right) d_{t} & =f, \\
\left(Q_{t}^{1}-R_{t}^{1}\right) & =\left(Q_{t}^{0}-R_{t}^{0}\right), \\
w_{t}^{b, 1}(x)-w_{t}^{b, 0}(x) & =\eta f .
\end{aligned}
$$

As expected, we obtain that the firing tax increases the difference both between the two job destruction rates and the two wages. Moreover the distance between $R_{t}$ and $Q_{t}$ is identical in new firms and old firms.

\subsection{Equilibrium}

Given initial conditions $K_{0}, N_{0}^{0}$ and $N_{0}^{1}$, an equilibrium is a vector of prices $\left\{\mathcal{P}_{t}\right\}_{t=0}^{\infty}=$ $\left\{w_{t}^{0}, w_{t}^{1}, r_{t}, d_{t}\right\}_{t=0}^{\infty}$ and a vector of quantities $\left\{\mathcal{Q}_{t}\right\}_{t=0}^{\infty}=\left\{\left\{\mathcal{Q}_{t}^{F}\right\}_{t=0}^{\infty},\left\{\mathcal{Q}_{t}^{H}\right\}_{t=0}^{\infty},\left\{\mathcal{Q}_{t}^{R}\right\}_{t=0}^{\infty}\right\}$, 
with $\left\{\mathcal{Q}_{t}^{F}\right\}_{t=0}^{\infty}=\left\{V_{t}, R_{t}^{F, 0}, R_{t}^{F, 1}\right\}_{t=0}^{\infty},\left\{\mathcal{Q}_{t}^{H}\right\}_{t=0}^{\infty}=\left\{C_{t}, S_{t}, R_{t}^{H, 0}, R_{t}^{H, 1}\right\}_{t=0}^{\infty}$ and $\left\{\mathcal{Q}_{t}^{R}\right\}_{t=0}^{\infty}=$ $\left\{Q_{t}, K_{t+1}\right\}_{t=0}^{\infty}$, such that:

- given a vector of prices $\left\{\mathcal{P}_{t}\right\}_{t=0}^{\infty},\left\{\mathcal{Q}_{t}^{F}\right\}_{t=0}^{\infty}$ is solution to the intermediate firms problem (equations (8), (9) and (10))

- given a vector of prices $\left\{\mathcal{P}_{t}\right\}_{t=0}^{\infty},\left\{\mathcal{Q}_{t}^{H}\right\}_{t=0}^{\infty}$ is solution to the household's problem (equations (12) and (18))

- given a vector of prices $\left\{\mathcal{P}_{t}\right\}_{t=0}^{\infty},\left\{\mathcal{Q}_{t}^{R}\right\}_{t=0}^{\infty}$ is solution to the final firm problem (equation (21))

- given a vector of quantities $\left\{\mathcal{Q}_{t}\right\}_{t=0}^{\infty},\left\{\mathcal{P}_{t}\right\}_{t=0}^{\infty}$ clears the capital and the goods markets (equations (14) and (24))

- wages are set according to the wage determination mechanism (equations (25), (26) and (29))

\section{Calibration}

To evaluate the quantitative effects of institutions on the behavior of the labor market, the model, in quarterly data, will be first calibrated at the steady state. We base our calibration on Mortensen and Pissarides $[17]^{16}$ and the empirical facts presented in section 2 to reproduce a representative EU labor market. We adopt the following specific functions:

$$
\begin{aligned}
\mathcal{F}(K, Q) & =\bar{\varepsilon}(K)^{\mu}(Q)^{1-\mu} \\
\mathcal{U}(C) & =\ln (C) \\
\mathcal{M}(V, \mathcal{S}(S) U) & =\bar{m}(V)^{\lambda}(\mathcal{S}(S) U)^{1-\lambda} \\
\mathcal{S}(S) & =\sigma_{0}+\sigma_{1} \frac{S^{\sigma_{2}}}{\sigma_{2}} \\
\mathcal{D}^{S}(S) & =\phi_{0}^{S}+\phi_{1}^{S} \frac{S^{\phi_{2}^{S}}}{\phi_{2}^{S}} \\
\mathcal{D}^{N}(N) & =\phi_{0}^{N}+\phi_{1}^{N} \frac{N^{\phi_{2}^{N}}}{\phi_{2}^{N}} .
\end{aligned}
$$

\footnotetext{
${ }^{16}$ They calibrate their model to represent the European employment experience over the last 20 years, in quarterly data.
} 
The production function $\mathcal{F}$ is Cobb-Douglas with constant returns to scale, where $\bar{\varepsilon}$ is an aggregate productivity parameter and $\mu$ is the capital-output elasticity; and the utility function $\mathcal{U}$ is logarithmic. As in Mortensen and Pissarides [17], the matching process $\mathcal{M}$ is represented by a Cobb-Douglas function with constant returns to scale. $\bar{m}$ is the exogenous matching efficiency and $\lambda$ is the elasticity of matches with respect to the vacancies. The search efficiency function $\mathcal{S}$ is concave whereas the disutility functions $\mathcal{D}^{S}$ and $\mathcal{D}^{N}$ are convex.

The depreciation rate $\delta$ of capital is set at $2.5 \%$ while the psychological discount factor $\beta$ is 0.99 , implying an annual interest rate of $4 \%$. The aggregate productivity shock is normalized to 1 , and $\mu=0.33$ to have a capital-output ratio of about 9 . In the literature, estimations of the matching function for European countries generally exhibit high elasticities of matches with respect to unemployment, in the range of 0.5-0.7 (see for instance Pissarides and Petrongolo [26]). We choose an intermediate value $1-\lambda=0.6$. The household's bargaining power is set equal to the workers' parameter of the matching function, i.e. $\eta=1-\lambda^{17}$. The cost of keeping a vacancy open is usually estimated to be small. Using a representative sample of French establishments, Abowd and Kramarz [1] estimate an average hiring cost per hire equivalent to $3.25 \%$ of the annual gross labor cost. If compared to the net labor cost (as in our model), this ratio will however be substantially higher. We fix $a=0.2$ which gives a ratio between hiring cost per hire and annual average wage of around $7 \%$, a figure similar to Mortensen and Pissarides [17].

Table 2 shows that the net replacement ratio is higher than 0.50 in most EU countries. This ratio must nevertheless be seen as an upper bound since it does not account for eligibility criteria and the very long unemployment spell duration. In our model, we fix the replacement ratio to 0.43 which gives an unemployment benefit $w^{u}=0.44$. The cost arising from employment protection is also expected to be high in EU countries but is more difficult to estimate. In our model, $f$ is a firing tax (which encompasses the cost of administrative procedurals, of social protests,...) rather than a severance payment. We therefore follow Mortensen and Pissarides [17] who estimate this cost to be about three times as large as

\footnotetext{
${ }^{17}$ See for instance Andolfatto [2] and Mertz [15] for a similar assumption. Their motivation is that this so-called Hosios condition implies, in their simpler model, a competitive equilibrium of the decentralized economy equivalent to the equilibrium of the social planner's problem.
} 
the cost of keeping a vacancy open and we set $f=0.50$. We do not have direct data about wage rigidities but a good proxy is the level of the minimum wage. Table 2 reports a gross Kaitz index above 0.50 in the EU countries. The net Kaitz index is therefore higher and we fix it to 0.58 in our model leading to a minimum wage level $w^{m}=0.6$. This minimum wage furthermore allows us to have $14 \%$ of the employed paid at the minimum wage (the OECD [22] reports for instance a figure of $11 \%$ for France in 1996) and a D9/D1 ratio of 2.5, which seems realistic enough.

Following Mortensen and Pissarides [17], we simply assume a uniform distribution for the idiosyncratic shocks $F(x)=x, \forall x \in[0,1]$. It remains to determine the 9 following parameters: $\bar{m}, \sigma_{i}$ and $\phi_{i}^{j}$, with $i \in\{0,1,2\}$ and $j \in\{S, N\}$. By simplicity, the independent terms of the search and disutility functions are set to $0\left(\sigma_{0}=\phi_{0}^{j}=0\right)$, the slope parameters of the search and the search disutility functions are set to $1\left(\sigma_{1}=\phi_{1}^{S}=1\right)$, and the curvature parameter $\phi_{2}^{N}$ (resp. $\phi_{2}^{N}$ ) of the search (resp. work) disutility function is set to 2 (resp. to 1) to have a quadratic (resp. linear) function. $\bar{m}, \sigma_{2}$ and $\phi_{1}^{N}$ are finally determined so as to recover particular steady state values for the unemployment rate, the mean duration of the unemployment spell, and the job destruction rate. As reproduced in table 2, the average unemployment rate in the beginning of the 1990's was around $10 \%$ in the EU countries; and is still at this level nowadays. In their model calibrated on Europe, Mortensen and Pissarides [17] use an average unemployment spell duration of 9 months (instead of 3 months in their calibration on US). We follow them and take an almost similar figure of 2.4 quarters for the average unemployment spell duration. As shown in section 2 , the average annual job turnover is estimated to be in between $15 \%$ and $25 \%$ in the EU countries. Taking the mean value $(20 \%)$ leads to an annual job destruction rate of $10 \%{ }^{18}$ and therefore a quarterly job destruction rate of $2.5 \%$. However, it is an underestimation because this figure does not take into account the jobs created and destroyed within the year. Taking this into account, we eventually set the job destruction rate $\chi^{1}=4 \%$. All our calibration is summarized in table 3 . This calibration is robust in the sense that small changes in parameters do not affect the qualitative results presented in the next section.

\footnotetext{
${ }^{18}$ At the steady state, the job creation is equal to the job destruction.
} 


\section{Simulations}

In this section, we simulate our model under alternative scenarios, both at the steady state and dynamically, to study the role of labor market institutions on the unemployment rate and the job flows. The unemployment rate $U_{t}$ is defined by equation (1). Using a uniform idiosyncratic shock distribution (see the calibration section), we have the job destruction rate $J D_{t}=R_{t}^{1}$, while the job creation rate $J C_{t}$ is:

$$
J C_{t}=\frac{\left(1-R_{t}^{0}\right) M_{t-1}}{N_{t-1}} .
$$

The job turnover $J T_{t}$ and the net employment change $N E T_{t}$ are respectively the sum and the difference between these two rates:

$$
\begin{aligned}
J T_{t} & =J C R_{t}+J D R_{t}, \\
N E T_{t} & =J C R_{t}-J D R_{t}=\frac{N_{t}-N_{t-1}}{N_{t-1}} .
\end{aligned}
$$

\subsection{Steady state effects}

We shock our three institutional parameters (the unemployment benefit $w^{u}$, the lower bound $w^{m}$ for the bargained wage and the firing tax $f$ ) and we focus on the long run effects on the main variables and especially on the unemployment rate. The results are displayed in table 4

A $10 \%$ increase in the unemployment benefit reduces the household's search effort, thereby lengthening unemployment duration by $8.3 \%$. This is in line with the result of Layard et al. [13] according to which the elasticity of the unemployment duration to the unemployment benefit is estimated to be in between 0.2 and 0.9 . By strenghtening the worker's bargaining position, an increase in $w^{u}$ have a direct positive impact on the bargained wages. The destruction rate and the average wage increase, unemployment rises and output falls. We hence recover empirical and theoretical results showing a negative relationship between the unemployment benefit and the employment level. It is worth noting that a shock on the unemployment benefit affects new jobs and old jobs in a similar way.

A strengthening of the wage rigidities via a $10 \%$ increase in $w^{m}$ augments the job destruction rate and the fraction of workers paid at the lower bound wage. The average wage is determined by the lower bound wage, the bargained wages and the job destruction rate, 
which also determines the fraction of workers paid at the minimum wage. The effect of $w^{m}$ on the bargained wage is ambiguous. Through equation (30), we see there is a direct positive effect (stronger bargaining position) but also an indirect negative effect due to the increase in the critical productivity value $Q$ (see equation (28)). The effects of $w^{m}$ on the job destruction rate and the fraction of workers paid at the minimum wage is however clearly positive and, despite this ambiguous evolution of the bargained wage, the higher lower bound wage and the higher job destruction rate are sufficient to ensure a higher average wage. This is strongly unfavorable to employment and output. These effects are similar for both new and old jobs. Our model hence illustrates the adverse effects of wage rigidities on employment, underlined by several empirical studies.

In Mortensen and Pissarides [17]'s model with complete wage flexibility, job protection leads to positive effects on employment. Indeed, an increase in the firing tax leads to lower job destruction, but also lowers job creation and therefore increases the unemployment duration. This, in turn, negatively affects the bargaining power of the worker and leads to a decrease in the average wage. Altogether, employment is stimulated. We find similar results with our model. However, in our setting, due to the introduction of wage rigidities, the downward wage adjustment is limited and hence the positive effect on employment. As shown in table 4 , a $10 \%$ increase in $f$ reduces unemployment rate by only 0.7 percentage point. For high levels of wage rigidities, the downward wage adjustment could even become too small to compensate the negative impact on profits of the firing tax and the unemployment rate could increase. We illustrate these interactions between $f$ and $w^{m}$ in figure 1 . We reproduce the effects on the unemployment rate of a $10 \%$ increase in the firing tax, for different levels for the lower bound wage. We see that the effect is negative for low wage rigidities, whereas it becomes positive for high wage rigidities (see Cahuc and Zylberberg [7] for a similar conclusion). However, whatever the level of $w^{m}$, the effect of $f$ on the unemployment rate is quite small, which is in accordance with empirical results showing no real significant relationship between employment protection and employment.

As a conclusion, if both the unemployment benefit and the wage rigidities may contribute to a high unemployment rate, the quantitative effect of the latter is much larger. Moreover, these rigidities are also important since they reduce the positive effects on employment of the firing tax. With respect to the employment criterion, protecting employment seems 
therefore irrelevant in a country with high wage rigidities.

\subsection{Cyclical properties}

We checked in the previous section the effects of institutions on the unemployment rate. We now focus on the effects of institutions on the cyclical properties of the job flows. We first examine the cyclical characteristics of the reference calibration and next look at the effects of institutional changes. To dynamically simulate our model, we introduce an autocorrelated aggregate productivity shock. In equation (34), $\bar{\varepsilon}$ is replaced by:

$$
\varepsilon_{t}=\bar{\varepsilon}^{1-\gamma} \varepsilon_{t-1}^{\gamma} e^{u_{t}}
$$

where $\gamma$ is the coefficient of autocorrelation and $u_{t}$ is drawn from a normal distribution $N\left(0, \sigma^{u}\right)$. As in Den Haan et al. [10], we set $\gamma=0.95$ and we calibrate $\sigma^{u}=0.03$ in order to have realistic volatilities for the job flows. We simulate our model during 10000 periods and table 5 displays the main cyclical properties for the job flows.

The job flows are highly autocorrelated and, by calibration, their volatilities are similar to those observed in table 1 , even if the relative job destruction volatility may be somewhat too high for a European economy. We also obtain the job creation rate procyclicality (with respect to the net employment change) and the job destruction rate countercyclicality observed in the data. The job turnover is more acyclical, as seems to be the case in EU countries.

In table 6, we vary our three institutional parameters (total variation of 20\%) and we evaluate their effects on the relative volatility of the job destruction rate and the cyclicality of the job turnover. If unemployment benefit has almost no effects on the cyclical properties, more wage rigidities lead to a lower relative volatility of the job destruction and a less countercyclical job turnover. This institutional feature may thus contribute to explain the cyclical properties of EU labor market (see section 2). The effects of changes in $w^{m}$ on the cyclical properties may work through both the job destruction rate and the job creation rate. However, in our model with high employment protection, the effects of $w^{m}$ on the cyclical properties of job destruction are weak. Most of the effects go through the job creation rate. With complete wage flexibility, the effects of aggregate productivity shock on job creation would be partly offset by higher wages. With wage rigidities, the wage effect is weakened 
because most of the wages remain unchanged at the lower bound wage, the productivity shock can fully positively affect the economy and the job creation effect is stronger than without wage rigidities. This explains the lower relative job destruction volatility and less countercyclical job turnover.

An increase in the firing tax (bottom part of table 6) increases the relative volatility of the job destruction rate and the countercyclicality of the job turnover. Again, due to job protection, all the effects of changes in $f$ mainly affects the cyclical properties of the job creation rate and not of the job destruction rate. Higher job protection decreases the volatility of the job turnover and therefore the volatility of the job creation rate. As a result, the relative volatility of the job destruction increases and the job turnover is more countercyclical (relative effect of job destruction cyclicality more important).

Wage rigidities and employment protection thus have opposite effects; and job protection does not seem to explain cyclical properties of a European labor market.

\section{Conclusion}

The aim of this paper is to study the role of labor market institutions on unemployment rate and job flows cyclical properties. The respective effects on unemployment of the unemployment benefit and the firing cost have already been extensively studied (both empirically and theoretically), but mainly in partial equilibrium market models. Moreover, the role of downward wage rigidities is not so well known.

We construct a stochastic intertemporal general equilibrium model with search unemployment and endogenous job turnover and three labor market institutions: unemployment benefits, a firing tax and a downward wage rigidity. We assume that wages are (re)negotiated at each period of time (usual Nash bargaining) but we introduce an institutionally fixed lower bound on this wage bargaining outcome. The model is calibrated on a European economy and simulated.

We obtain that high unemployment benefit and, especially, high wage rigidities are able to explain high unemployment. The effect of the firing tax on unemployment is more ambiguous and depends on the level of wage rigidities. However, whatever its direction, this effect is quite small. Focusing on job flows cyclical properties, we see that our model is able to 
reproduce the countercyclicality of the job destruction rate, the procyclicality of the job creation rate and, as a result, the acyclicality of the job turnover. We moreover find that the wage rigidities and the firing tax have opposite effects on the job flows cyclical properties and that it is the high wage rigidities that seems to explain the cyclical properties of a European labor market.

Downward wage rigidities thus may well be apt to play a key role in explaining EU-US differences, both in terms of unemployment rate and cyclical properties. The result is in line with available empirical results emphasizing the role of wage formation and stressing that high employment is associated with low wage levels and high levels of wage inequality. Our results are robusts in the sense that moderate changes in the calibration do not alter the qualitative results. Naturally, such downward wage rigidities cannot be captured by a single "minimum wage" parameter. The specification adopted here to introduce them remained quite simple albeit sufficient to make the point, and may serve as a starting point for future developments. 


\section{References}

[1] Abowd, J. and F. Kramarz, 1997, The costs of hiring and separations, CREST Working Paper no. 9543 .

[2] Andolfatto, D., 1996, Business Cycles and Labor-Market Search, American Economic Review vol. 86(1), pp. 112-132.

[3] Bertola, G., F. Blau and L. Kahn, 2001, Comparative analysis of labor market outcomes: lessons for the US from international long-run evidence, NBER Working Paper no. 8526.

[4] Blanchard, O. and J. Wolfers, 2000, The role of shocks and institutions in the rise of European unemployment: the aggregate evidence, Economic Journal, vol. 110, pp.1-33.

[5] Boeri, T., 1996, Is turnover is countercyclical?, Journal of Labor Economics, vol. 14(4), pp. 603-625.

[6] Caballero, J. and M. Hammour, 1996, On the timing and the efficiency effect of creative destruction, Quartely Journal of Economics, vol. 111, pp. 805-852.

[7] Cahuc, P. and A. Zylberberg, 1999, Job protection, minimum wage, and unemployment, IZA Discussion Paper no. 95.

[8] Coe, D. and D. Snower, 1997, Policy Complementarities: The Case for Fondamental Labor Market Reform, IMF Staff Paper, vol. 44(1), pp. 1-35.

[9] Davis S., J. Haltiwanger and S. Schuh, 1996, Job creation and destruction, The MIT Press.

[10] Den Haan, W., G. Ramey and J. Watson, 2000, Job destruction and propagation of shocks, American Economic Review, vol. 90, pp. 482-498.

[11] Garibaldi, P., 1998, Job flow dynamics and firing restrictions, European Economic Review, vol. 41, pp. $245-275$.

[12] Holmund, B., 1998, Unemployment insurance in theory and practise, Scandinavian Journal of Economics, vol. 100(1), pp. 113-141.

[13] Layard R., S. Nickell and R. Jackman, 1991, Unemployment: Macroeconomic performance and the labour market, Oxford University Press

[14] Ljungqvist, L., 2002, How do lay-off costs affect employment, The Economic Journal, vol. 112, pp. 829-853.

[15] Merz, M., 1995, Search in the labor market and the real business cycle, Journal of Monetary Economics, vol. 36, pp. 269-300. 
[16] Mortensen, D. and C. Pissarides, 1994, Job creation and job destruction, Review of Economic Studies, vol. 1, pp. 733-753.

[17] Mortensen, D. and C. Pissarides, 1999, Job reallocation, employment fluctuations and unemployment, In Handbook of Macroeconomics, 1, edited by J. Taylor and M. Woodford, Elsevier Science.

[18] Nickell, S., 1997, Unemployment and labor market rigidities: Europe versus North America, Journal of Economic Perspectives, vol. 11(3), pp. 55-74.

[19] OECD, 1994, Employment Outlook, Paris.

[20] OECD, 1994, Employment Study, Paris.

[21] OECD, 1996, Employment Outlook, Paris.

[22] OECD, 1998, Employment Outlook, Paris.

[23] OECD, 1999, Employment Outlook, Paris.

[24] OECD, 2002. Benefits and Wages, Paris.

[25] Pierrard, O. and H. Sneessens, 2003, Low-skilled unemployment, biased technological shocks and job competition, IZA Discussion Paper no. 784 .

[26] Petrongolo, B. and C. Pissarides, 2001, Looking back into the black box: a survey of the matching function, Journal of Economic Literature, vol. 39, pp. 390-431. 


\begin{tabular}{lcccccc}
\hline Country & $J T$ & $N E T$ & $\sigma(J C)$ & $\sigma(J D)$ & $\sigma(J D) / \sigma(J C)$ & $U$ \\
& & & & & & \\
\hline & & & & & & \\
Belgium & $15.2 \%$ & $0.2 \%$ & - & - & - & $11.2 \%$ \\
France & $24.4 \%$ & $0.9 \%$ & 1.7 & 0.9 & 0.53 & $9.9 \%$ \\
Germany & $16.5 \%$ & $1.5 \%$ & 0.8 & 0.8 & 1.0 & $7.5 \%$ \\
Italy & $21.0 \%$ & $1.0 \%$ & 1.2 & 0.9 & 0.7 & $9.3 \%$ \\
Netherlands & $15.4 \%$ & $1.0 \%$ & - & - & - & $7.7 \%$ \\
United States & $18.6 \%$ & $2.6 \%$ & 2.0 & 3.0 & 1.5 & $6.8 \%$ \\
& & & & & & \\
\hline
\end{tabular}

Yearly data. JT: job turnover, average 1984-1991 (may vary according to the country), source: OCDE [21], table 5.1, p.163. NET: net employment change, average 1984-1991 (may vary according to the country), source: OCDE [21], table 5.1, p.163. $\sigma(J C)$ : job creation standard deviation, average 1980's (may vary according to the country), HP filtered, source: Boeri [5]. $\sigma(J D)$ : job destruction standard deviation, average 1980's (may vary according to the country), HP filtered, source: Boeri [5]. $U$ : unemployment rate, average 1983-1993, source: OCDE [21], table 1.3, p.4.

Table 1: Job flows and unemployment: some facts

\begin{tabular}{lcccc}
\hline Country & Repl. ratio & EPL strictness & Kaitz index & Wage dispersion \\
& & & & \\
\hline & & & & \\
Belgium & 0.70 & $2.1(13)$ & 0.53 & 2.2 \\
France & 0.52 & $3.0(21)$ & 0.55 & 3.3 \\
Germany & 0.63 & $2.5(18)$ & - & 2.3 \\
Italy & 0.13 & $3.3(23)$ & - & 2.8 \\
Netherlands & 0.76 & $2.1(14)$ & 0.51 & 2.6 \\
United States & 0.32 & $0.2(1)$ & 0.35 & 4.4 \\
& & & & \\
\hline
\end{tabular}

Repl. ratio: synthetical net replacement ratio, 1999, source: OECD [24], table 3.10, p.41. EPL strictness: synthetical index of the strictness of employment protection legislation and country ranking (between brackets), late 1990's, source: OCDE [23], table 2.5, p.66. Kaitz index: gross Kaitz index, mid-1997, source: OCDE [22], table 2.3, p.37. Wage dispersion: gross D9/D1 ratio, 1995 (may vary according the country), source: OCDE [21], table 3.1, p.62.

Table 2: Labor market institutions: some facts 


\begin{tabular}{|c|c|c|c|c|c|}
\hline Symbol & Value & Symbol & Value & Symbol & Value \\
\hline \multicolumn{6}{|c|}{ Matching function } \\
\hline $\bar{m}$ & 0.60 & $\lambda$ & 0.4 & & \\
\hline \multicolumn{6}{|c|}{ Production function } \\
\hline $\bar{\varepsilon}$ & 1 & $\mu$ & 0.33 & & \\
\hline \multicolumn{6}{|c|}{ Search function } \\
\hline$\sigma_{0}$ & 0 & $\sigma_{1}$ & 1 & $\sigma_{2}$ & 0.55 \\
\hline \multicolumn{6}{|c|}{ Disutility functions } \\
\hline$\phi_{0}^{S}$ & 0 & $\phi_{1}^{S}$ & 1 & $\phi_{2}^{S}$ & 2 \\
\hline$\phi_{0}^{N}$ & 0 & $\phi_{1}^{N}$ & 0.16 & $\phi_{2}^{N}$ & 1 \\
\hline \multicolumn{6}{|c|}{ Costs } \\
\hline$a$ & 0.20 & $f$ & 0.50 & & \\
\hline \multicolumn{6}{|c|}{ Wages determination } \\
\hline$\eta$ & 0.60 & $w^{u}$ & 0.44 & $w^{m}$ & 0.60 \\
\hline \multicolumn{6}{|c|}{ Psychological discount and capital depreciation } \\
\hline$\beta$ & 0.99 & $\delta$ & 0.025 & & \\
\hline
\end{tabular}

Table 3: Numerical parameter values

\begin{tabular}{lcccccc}
\hline & $\mathcal{F}$ & $J T$ & $U$ & pop $w^{m}$ & $U$ duration & $\bar{w}$ \\
& & & & & & \\
\hline & & & & & & \\
benchmark & 1.43 & $9.8 \%$ & $10.5 \%$ & $14.5 \%$ & 2.4 & 1.03 \\
$w^{u}(+10 \%)$ & $-2.0 \%$ & +2.1 & +2.6 & -1.0 & $+8.3 \%$ & $+0.5 \%$ \\
$w^{m}(+10 \%)$ & $-4.0 \%$ & +6.8 & +6.9 & +4.6 & $+5.7 \%$ & $+1.6 \%$ \\
$f(+10 \%)$ & $+0.2 \%$ & -1.3 & -0.7 & +0.6 & $+6.5 \%$ & $-0.3 \%$ \\
\hline
\end{tabular}

pop $w^{m}$ : percentage of the workers paid at the lower bound wage. $U$ duration: mean unemployment spell duration (expressed in quarters). $\bar{w}$ : mean wage.

Table 4: Long run effects of institutional shocks (deviations from the benchmark) 
$\triangle \mathrm{U}$

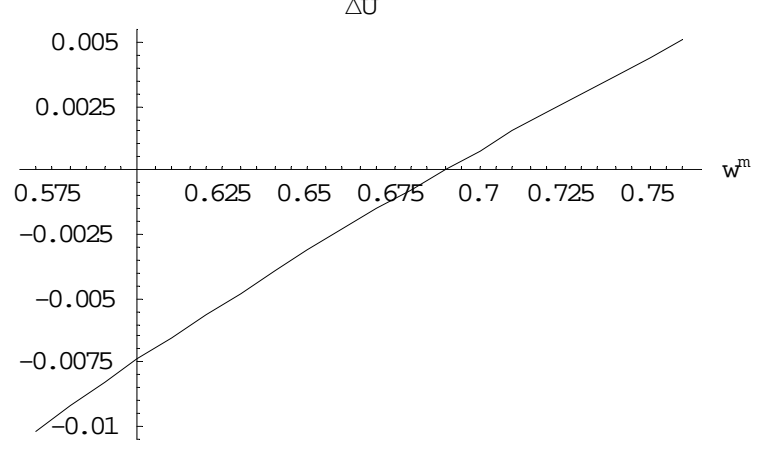

Figure 1: Effect on unemployment of a firing tax $10 \%$ increase, for different values of $w^{m}$

\begin{tabular}{lccc}
\hline & & & \\
& $J C_{t}$ & $J D_{t}$ & $J T_{t}$ \\
& & & \\
\hline \multirow{2}{*}{$(1)$} & 0.88 & 0.69 & 0.89 \\
$\sigma$ & 0.82 & 1.00 & 1.50 \\
$\operatorname{corr}\left(., N E T_{t}\right)$ & 0.46 & -0.68 & -0.21 \\
& & & \\
\hline
\end{tabular}

All series are HP filtered. $A R(1)$ : autocorrelation of order 1. $\sigma$ : standard deviation. $\operatorname{corr}\left(., N E T_{t}\right)$ : correlation with respect to net employment change.

Table 5: Cyclical properties of job flows in reference calibration 


\begin{tabular}{lccccc}
\hline & & & & & \\
$w^{u}=$ & 0.40 & 0.42 & $\mathbf{0 . 4 4}$ & 0.462 & 0.484 \\
$\sigma\left(J D_{t}\right) / \sigma\left(J C_{t}\right)$ & 1.22 & 1.21 & $\mathbf{1 . 2 2}$ & 1.21 & 1.21 \\
$\operatorname{corr}\left(J T_{t}, N E T_{t}\right)$ & -0.21 & -0.21 & $\mathbf{- 0 . 2 1}$ & -0.20 & -0.19 \\
& & & & & \\
\hline & & & & & \\
$w^{m}=$ & 0.54 & 0.57 & $\mathbf{0 . 6 0}$ & 0.63 & 0.66 \\
$\sigma\left(J D_{t}\right) / \sigma\left(J C_{t}\right)$ & 1.28 & 1.26 & $\mathbf{1 . 2 2}$ & 1.18 & 1.12 \\
$\operatorname{corr}\left(J T_{t}, N E T_{t}\right)$ & -0.27 & -0.24 & $\mathbf{- 0 . 2 1}$ & -0.16 & -0.12 \\
& & & & & \\
\hline & & & & & \\
$f=$ & 0.45 & 0.48 & $\mathbf{0 . 5 0}$ & 0.53 & 0.55 \\
$\sigma\left(J D_{t}\right) / \sigma\left(J C_{t}\right)$ & 1.20 & 1.20 & $\mathbf{1 . 2 2}$ & 1.24 & 1.26 \\
$\operatorname{corr}\left(J T_{t}, N E T_{t}\right)$ & -0.18 & -0.19 & $\mathbf{- 0 . 2 1}$ & -0.22 & -0.23 \\
& & & & & \\
\hline
\end{tabular}

All series are HP filtered. $\sigma$ : standard deviation. $\operatorname{corr}\left(., N E T_{t}\right)$ : correlation with respect to net employment change.

Table 6: Sensitivity of cyclical properties to $w^{u}, w^{m}$ and $f$ 